\title{
Ruminations about making a theoretical contribution
}

\author{
Victoria L. Crittenden • Robert A. Peterson
}

Published online: 13 October 2011

(C) Academy of Marketing Science 2011

More than half a century has transpired since Lyndon O. Brown ignited the flames of the "Is marketing a science?" debate (Brown 1948). Brown's article resulted in a chain reaction (Taylor 1965), with prominent scholars weighing in on the standards of science and marketing's metric against such standards (see Cox and Alderson 1948; Vaile 1949; Miller 1950; Bartels 1951; Hutchinson 1952; Buzzell 1963). As predicted by Taylor, the marketing profession has been successful at attaining "a period when a maximum number of trained minds exercising scientific skill will achieve greater speed in finding significant and useful relationships in an infinite unknown" (Taylor 1965, p. 50). Marketing scholars have exercised their scientific prowess via a large number of theory testing contributions (Yadav 2010). That is, marketing researchers have accomplished one tenet of the standards of science as delineated by Buzzell (1963, p. 32), “...usually expressed in quantitative terms." Marketing and non-marketing theories are purported to be tested regularly (and quantitatively) in our scholarly research.

Marketers' contributions to theoretical development are exemplified in tier-one marketing journals with common section headings such as "Theory," "Theoretical Analysis," "Theoretical Background," "Theoretical Development," and "Theoretical Framework and Hypothesis Development." Unfortunately, few of these theory-labeled sections actually propose or contain "theory" as it is construed from

V. L. Crittenden $(\bowtie)$

Carroll School of Management, Boston College,

Chestnut Hill, MA 02467, USA

e-mail: victoria.crittenden@bc.edu

R. A. Peterson

Office of the Vice President for Research,

The University of Texas at Austin,

Austin, TX 78713, USA

e-mail: rap@mail.utexas.edu a marketing science perspective. Merton (1967, p. 39) summarized this lack of theoretical contribution in our scholarly journals as, "Like so many words that are bandied about, the word theory threatens to become meaningless. Because its referents are so diverse-including everything from minor working hypotheses, through comprehensive vague and unordered speculations, to axiomatic systems of thought - use of the word often obscures rather than creates understanding." Unfortunately, the lack of agreement on what constitutes theory, much less how to write a conceptual/theoretical paper, has left marketing scholars confused, thus exacerbating the difficulty of engaging in theory development and testing.

In a recent AMS Quarterly, we opined briefly on theory construction and development, with the purpose of offering some guidance for producing theoretical/conceptual contributions in marketing (Crittenden and Peterson 2011). Drawing on the works of skilled theorists, the objective of this editorial is to provide a brief introduction to, and overview of, suggested frameworks and schemas for creating and developing theory.

\section{Definitions of theory}

A Google web search (2011) offered the following definitions of theory:

- A supposition or a system of ideas intended to explain something, especially one based on general principles independent of the thing to be explained

- A set of principles on which the practice of an activity is based

- An idea used to account for a situation or justify a course of action 
- A collection of propositions to illustrate the principles of a subject.

Further exploration within these definitions offered elaborations as to what constitutes a "scientific" theory:

- A theory that explains scientific observations; "scientific theories must be falsifiable"

- An explanation or idea accepted by a substantial number of scientists

- A hypothesis that is widely accepted by the scientific community

- An explanation of why and how a specific natural phenomenon occurs.

- A statement that postulates ordered relationships among natural phenomena

- A scientific theory is an explanation or model used to account for observations or experimental results characterizing an observed phenomenon.

Within the management/business discipline, illustrative definitions of theory abound. For example, theory has been viewed as

- "An ordered set of assertions about a generic behavior or structure assumed to hold throughout a significantly broad range of specific instances" (Sutherland 1975, p. 9)

- "A systematically related set of statements, including some lawlike generalizations, that is empirically testable" (Rudner 1966, p. 10)

- "A statement of relationships between units observed or approximated in the empirical world" (Bacharach 1989, p. 498)

- "A collection of assertions, both verbal and symbolic, that identifies what variables are important and for what reasons, specifies how they are interrelated and why, and identifies the conditions under which they should be related or not related" (Campbell 1990, p. 65)

Hambrick (2007, p. 1346) posited that "theories help us organize our thoughts, generate coherent explanations, and improve our predictions." Colquitt and Zapata-Phelan (2007, p. 1281) provided summary statements from a wide variety of researchers: "Theory allows scientists to understand and predict outcomes of interest, even if only probabilistically," "Theory also allows scientists to describe and explain a process or sequence of events," "Theory prevents scholars from being dazzled by the complexity of the empirical world by providing a linguistic tool for organizing it," "Theory acts as an educational device that can raise consciousness about a specific set of concepts," and "Theory is the basic aim of science." Yet, while the definitions appear straightforward and essentially say the same thing using different words and the importance of theory is inarguable, researchers continue to remain confused as to how to create and communicate a strong theory contribution (Freese 1980). For example, according to Sutton and Staw (1995, p. 371), "There is lack of agreement about whether a model and a theory can be distinguished, whether a typology is properly labeled a theory or not, whether the strength of a theory depends on how interesting it is, and whether falsifiability is a prerequisite for the very existence of theory."

Thus, rather than coalesce on a definition of theory, it is likely more beneficial to highlight the contributions of prominent theorists in an effort to provide the characteristics of good theory and the process of building good theory. The Academy of Management Review published several articles in 1989 that focused on criteria and methods for building good theory. We will draw from these and other articles in an effort to summarize what has been offered over time in terms of theoretical development.

\section{The process of theory development}

\section{Stimulate interest}

According to Davis (1971), a theorist is not considered great because his/her theories are true, but because the theories are interesting. Smith (2003) referred to noninteresting ideas as "so what?" ideas, with interesting ideas being the ones that elicited a strong visceral or emotional reaction from readers. In brief, both authors suggested that interesting theories or ideas deny assumptions that one would think true, while non-interesting theories or ideas only confirm what one suspected already.

Davis (1971) created what he refers to as the Index of the Interesting and examined a large number of propositions within sociological theories to isolate common elements of interest. Basically, he found that something interesting was the negation of the accepted truth - that is, what seemed to be X was actually non-X. Weick (1989) expanded on Davis' interesting phenomenon by offering a variety of selection criteria, which he aptly referred to as "disciplined imagination." In doing so, he enabled wouldbe theorists to assess their thinking against a wider attribute base. Weick's criteria are:

- "That's interesting"

- "That's obvious"

- "That's connected"

- "That's believable"

- "That's beautiful"

- "That's real." 
While not focused specifically on theory development, Smith (2003) offered seven suggestions for scoring high on what he referred to as the interesting Richter scale:

1. Test the assumptions on which a significant stream of research relies

2. Probe the external validity of what we take to be true

3. The next new thing-for example, probe contradictions between research and practice

4. Work backward in the causal chain

5. Intervene in the accepted causal chain

6. Challenge conventional managerial practices or beliefs

7. Resolve inconsistent findings.

According to Van de Ven (1989, p. 486), "we need to appreciate and strengthen our skills in developing good theory." The aforementioned scholars have attempted to aid in the theory development process by offering suggestions for putting structure around the theorizing process. Quoting Weick (1989, p. 516), "the discipline in theorizing comes from consistent application of selection criteria" and "the imagination in theorizing comes from deliberate diversity introduced into...that thinking."

Crafting theoretical/conceptual contributions

Clear articulation is important to the testing and future development of any theory (Hunt 1983). Lamenting the absence of a broadly-accepted framework for conceptual writing, Whetten (1989) reflected on how best to communicate the necessary ingredients of a theoretical contribution. Referencing other contributors to theory development, Whetten suggested that there are four essential elements that are the building blocks for a complete theory. The What element captures the factors that should be considered as part of the phenomena of interest. Following this, How is the element that shows the relationships between and among the identified factors (e.g., using arrows to connect boxes). The Why element is the rationale behind the model that explains the reason(s) for others to give credence to the representation. Finally, the fourth building block is comprised of Who, Where, and When, which are the conditions that place limitations on the propositions generated from the theoretical model.

Contributing to this dialogue, Bacharach (1989) focused considerable attention on the How element by distinguishing clearly between constructs and variables. While constructs and variables are related, they must be respectively isomorphic, and theorists should not use the terms synonymously (Bacharach 1989). The importance of constructs in theory development has been reaffirmed by numerous scholars. MacKenzie (2003, p. 325) stated, “... when you are having difficulty defining a construct, it is usually because you have not really decided what you want the construct to represent." Kaplan (1964, p. 53) referred to the importance of construct development and the linkage among the What, How, and Why elements in his paradox of conceptualization, stating, "The proper concepts are needed to formulate a good theory, but we need a good theory to arrive at the proper concepts."

The relationships among What, How, Why, Who, Where, and When are reflected in the propositions, since "the purpose of a proposition is to communicate the relationship between two or more constructs" (Bacharach 1989, p. 503). Accordingly, constructs and their related propositions must be falsifiable (construct validity, clarity and parsimony, logical and empirical adequacy) and possess utility (explanatory potential and predictive adequacy). The importance of constructs and their relationships as denoted in propositions in theory development cannot be overstated since propositions are the source of subsequent theory testing in that one theoretical proposition might be the source for numerous hypotheses.

Bergman (1957) suggested that a scientific theory is formalized by replacing descriptive words with marks on paper. A concept map or diagram enables the researcher to present his/her theory in a systematic format that in turn enables the organization of thoughts in a visually-appealing fashion. To this end, Hair et al. (2007) went so far as to offer guidance on the format to use to depict theoretical constructs. While a conceptual map or diagram is not absolutely necessary for theoretical explication, around $80 \%$ of the theory construction and development articles in a study done by Liehr and Smith (1999) provided a visual for communicating the How element of theory.

\section{Evaluating theoretical contributions}

As noted by a member of the AMS Review editorial board, reviewing a conceptual/theoretical manuscript is not easy. An understanding of what to look for from a reviewer's perspective is equally informative to the researcher attempting to craft a theoretical contribution. In evaluating (and preparing) a theoretical contribution, Kilduff (2006) explained theory development from various perspectives and offered guidance. For example, a logical positivist framework leads to propositions that are demonstrably testable, whereas new empirical research questions might be the result of drawing new ideas from core concepts in an ongoing research program. The perspective of Kuhn (1996), however, would be the articulation of puzzlesolving ideas within a current paradigmatic framework.

An important evaluative criterion for Bacharach (1989) was that a theory be testable - if not, it is not a theory as it does meet the falsifiability and utility criteria. Whetten (1989, p. 494) provided a list of seven key questions that 
are used to answer the question, "What constitutes a publishable theory paper?"

1. What's new? That is, does the paper make a significant, value-added contribution to current thinking?

2. So what? Will the theory likely change the practice of organizational science in the topical area?

3. Why so? Is the paper built on a foundation of convincing argumentation and grounded in practice?

4. Well done? Is the paper complete and thorough? That is, are the building blocks of a theory (What, How, Why, Who, When, Where) covered?

5. Done well? Is the paper well-written?

6. Why now? Is the contribution of contemporary interest to scholars?

7. Who cares? Is the contribution linked to core concepts and problems?

A perusal of the first issue of the Review shows four very different types of presentation styles. Even so, all four styles adhered to rigorous evaluative guidelines derived from literature.

\section{Mistaken for theory}

According to Hunt (1983), there are three criteria that distinguish a theoretical contribution from a non-theoretical contribution: (1) the systematically related criterion, (2) the lawlike generalizations criterion, and (3) the empirically testable criterion. However, it appears to be too easy for researchers to misinterpret each of these criteria. Thus, Sutton and Staw (1995) offered five very specific items that are often misconstrued as theory.

First, references are not theory. That is, illuminating an existing theory through referencing is not the same as explicating the causal logic within the theory's foundation. Thus, a traditional literature review as found in doctoral dissertations is not synonymous with making a contribution to theory. Second, empirical data are not theory. Theory explains why; empirical data describes the patterns that were observed in the theory testing. Price (2010) referred to the lack of a need for data in theoretical/conceptual pieces as a myth. However, while data (particularly qualitative) may have facilitated the development of a theory, the distinction is that a theory development article does not contain empirical data. Third, a list of the constructs is not theory. Relationships (How) posed between and among constructs are theoretical contributions-not the constructs in and of themselves. Fourth, diagrams are not theory. It is important that there be a verbal explanation to accompany a diagram that explains the logic underlying the relationships. Fifth, hypotheses are not theory. It is important to remember that theory development involves constructs and propositions, whereas theory testing utilizes variables and hypotheses. Constructs/propositions focus on why something is expected to occur, whereas hypotheses are statements about what is expected occur for testing purposes.

\section{In this issue}

Further elaborating on advice about theory development, Hunt (2011) in "Developing Successful Theories in Marketing: Insights from Resource Advantage Theory" has provided insights into what makes a theory great and offers five guides for authors seeking to develop successful theories in marketing. Drawing from his own very successful marketing theory that has in excess of a thousand citations, tens of thousands search engine hits, and garnered numerous awards, Hunt seeks to derive the characteristics of successful theories in marketing. Thus, the advice in his current article seeks to move beyond the mechanics of theory development, as we have offered here, to what it takes to make a mechanically accurate theory successful. Three commentators at varying stages in their academic careers, Schlegelmilch (2011), Brasel (2011), and Campbell (2011) have initiated a dialog regarding these insights.

Expanding the theoretical domain within marketing, while also offering an example of middle range theory (see Colquitt and Zapata-Phelan (2007) for a discussion of middle range theory), is the intent of the article by Karande et al. (2011). Exploring innovativeness as related to new product introductions, the authors offer insights into what they refer to as an underexplored construct while also introducing new moderators of an existing relationship. In doing so, the authors both clarify and supplement existing theory.

Each of the major articles in this issue makes a significant contribution to theory development in marketing. The commentaries provide additional perspectives on the impact successful theory development in marketing can have on scholars and their research careers.

\section{References}

Bacharach, S. B. (1989). Organizational theories: Some criteria for evaluation. Academy of Management Review, 14(4), 496-515.

Bartels, R. T. (1951). Can marketing be a science? Journal of Marketing, 15(3), 319-328.

Bergman, G. (1957). Philosophy of science. Madison: University of Wisconsin Press.

Brasel, S. A. (2011). Systematic reflection as a learning opportunity. AMS Review, 1(2). 
Brown, L. O. (1948). Toward a profession of marketing. Journal of Marketing, 13(1), 27-31.

Buzzell, R. D. (1963). Is marketing a science? Harvard Business Review, 41(1), 32-40.

Campbell, C. (2011). Commentary on 'developing successful theories in marketing: Insights from resource advantage theory.' $A M S$ Review, 1(2).

Campbell, J. P. (1990). The role of theory in industrial and organizational psychology. In M. D. Dunnette \& L. M. Hough (Eds.), Handbook of industrial and organizational psychology, vol. 1. Palo Alto: Consulting Psychologists.

Colquitt, J. A., \& Zapata-Phelan, C. P. (2007). Trends in theory building and theory testing: A five-decade study. Academy of Management Journal, 50(6), 1281-1303.

Cox, R., \& Alderson, W. (1948). Towards a theory of marketing. Journal of Marketing, 13(2), 137-152.

Crittenden, V. L., \& Peterson, R. A. (2011). Notes on crafting theory. AMS Quarterly, 11(4), 3.

Davis, M. S. (1971). That's interesting! Towards a phenomenology of sociology and a sociology of phenomenology. Philosophy of the Social Sciences, 1(4), 309-344.

Freese, L. (1980). Formal theorizing. Annual Review of Sociology, 6, $187-212$.

Google web search (2011). Theory. Retrieved August 17, 2011 from http://www.google.com/search?\&ie=UTF-8\&q=define + hello\#hl $=$ en $\& \mathrm{sa}=\mathrm{X} \& \mathrm{ei}=\mathrm{kqhLTo} 3 \mathrm{WMcmcgQe} 0$ zaxz\&ved $=0 \mathrm{CBgQ}$ vwUoAQ\&q $=$ define + theory\&spell $=1 \& b a v=$ on.2,or.r_gc.r_pw. $\& f p=f b 9 a 7 a 497 d 49 d f 1 a \& b i w=1280 \& b i h=671$.

Hair, J., Money, A., Samouel, P., \& Page, M. (2007). Research methods for business. United Kingdom: Wiley.

Hambrick, D. C. (2007). The field of management's devotion to theory: Too much of a good thing? Academy of Management Journal, 59(6), 1346-1352.

Hunt, S. D. (1983). Marketing theory: The philosophy of marketing science. Homewood: Richard D. Irwin, Inc.

Hunt, S. D. (2011). Developing successful theories in marketing: Insights from resource advantage theory. AMS Review, 1(2).

Hutchinson, K. D. (1952). Marketing as a science: An appraisal. Journal of Marketing, 16(3), 286-293.

Kaplan, A. (1964). The conduct of inquiry: Methodology for behavioral science. San Francisco: Chandler.

Karande, K., Merchant, A., Sivakumar, K. (2011). Relationships among time orientation, consumer innovativeness, and innova- tive behavior: The moderating role of product characteristics. AMS Review, 1(2).

Kilduff, M. (2006). Editor's comments: Publishing theory. Academy of Management Review, 31(2), 252-255.

Kuhn, T. S. (1996). The structure of scientific revolutions (3rd ed.). Chicago: University of Chicago Press.

Liehr, P., \& Smith, M. J. (1999). Middle range theory: Spinning research and practice to create knowledge for the new millennium. Advances in Nursing Science, 21(4), 81-91.

MacKenzie, S. B. (2003). The dangers of poor construct conceptualization. Journal of the Academy of Marketing Science, 31(3), 323-326.

Merton, R. K. (1967). On theoretical sociology. New York: Free Press.

Miller, N. E. (1950). Social science and the art of advertising. Journal of Marketing, 14(4), 579-584.

Price, L. (2010). Thinking theoretically. Presentation, Academy of Marketing Science annual conference, Portland, Oregon, May 26-29.

Rudner, R. (1966). Philosophy of social science. Englewood Cliff: Prentice-Hall.

Schlegelmilch, B. (2011). Commentary on 'developing successful theories in marketing: Insights from resource advantage theory.' AMS Review, 1(2).

Smith, D. C. (2003). The importance and challenges of being interesting. Journal of the Academy of Marketing Science, 31 (3), 319-322.

Sutherland, J. W. (1975). Systems: Analysis, administration, and architecture. New York: Van Nostrand.

Sutton, R. I., \& Staw, B. M. (1995). What theory is not. Administrative Science Quarterly, 40(3), 371-384.

Taylor, W. J. (1965). Is marketing a science? revisited. Journal of Marketing, 29(3), 49-53.

Vaile, R. S. (1949). Towards a theory of marketing - a comment. Journal of Marketing, 13(4), 520-522.

Van de Ven, A. H. (1989). Nothing is quite so practical as a good theory. Academy of Management Review, 14(4), 486-489.

Weick, K. E. (1989). Theory construction as disciplined imagination. Academy of Management Review, 14(4), 516-531.

Whetten, D. A. (1989). What constitutes a theoretical contribution? Academy of Management Review, 14(4), 490-495.

Yadav, M. S. (2010). The decline of conceptual articles and implications for knowledge development. Journal of Marketing, 74(1), 1-19. 